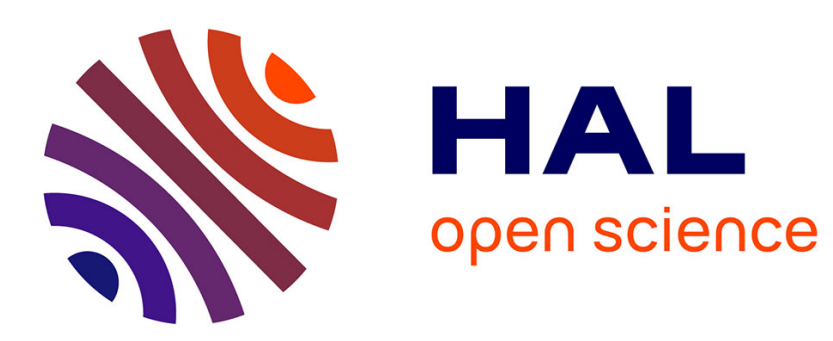

\title{
Passive geoacoustic inversion with a single hydrophone using broadband ship noise
}

Cedric Gervaise, Bazile Kinda, Julien Bonnel, Yann Stéphan, Simon Vallez

\section{To cite this version:}

Cedric Gervaise, Bazile Kinda, Julien Bonnel, Yann Stéphan, Simon Vallez. Passive geoacoustic inversion with a single hydrophone using broadband ship noise. Journal of the Acoustical Society of America, 2012, 131 (3), pp.1999-2010. hal-00857182v2

\section{HAL Id: hal-00857182 \\ https://hal.science/hal-00857182v2}

Submitted on 3 Sep 2013

HAL is a multi-disciplinary open access archive for the deposit and dissemination of scientific research documents, whether they are published or not. The documents may come from teaching and research institutions in France or abroad, or from public or private research centers.
L'archive ouverte pluridisciplinaire HAL, est destinée au dépôt et à la diffusion de documents scientifiques de niveau recherche, publiés ou non, émanant des établissements d'enseignement et de recherche français ou étrangers, des laboratoires publics ou privés. 


\title{
Passive geoacoustic inversion with a single hydrophone using broadband ship noise
}

\author{
C. Gervaise ${ }^{\text {a) }}$ \\ GIPSA Lab, CNRS, Grenoble INP, 11 Rue des Mathématiques, Domaine Universitaire, 38402 Saint Martin \\ d'Héres, France
}

B. G. Kinda and J. Bonnel

Pôle STIC/Team Passive Acoutics, EA3876, ENSTA Bretagne, 2 rue François Verny, 29806 Brest Cedex 9 , France

\author{
Y. Stéphan \\ Service Hydrographique et Océanographique de la Marina (SHOM), 13 rue Chatelier CS 92803, 29228 Brest \\ cedex 2, France.
}

\author{
S. Vallez \\ SERCEL, 12 rue Villeneuve, 29200 Brest, France
}

(Received 28 April 2011; revised 18 November 2011; accepted 21 November 2011)

\begin{abstract}
An inversion scheme is proposed, relying upon the inversion of the noise of a moving ship measured on a single distant hydrophone. The spectrogram of the measurements exhibits striations which depend on waveguide parameters. The periodic behavior of striations versus range are used to estimate the differences of radial wavenumber between couples of propagative modes at a given frequency. These wavenumber differences are stacked for several frequencies to form the relative dispersion curves. Such relative dispersion curves can be synthesized using a propagation model feeded with a bottom geoacoustic model. Inversion is performed by looking for the bottom properties that optimize the fit between measured and predicted relative dispersion curves. The inversion scheme is tested on simulated data. The conclusions are twofold: (1) a minimum $6 \mathrm{~dB}$ signal to noise ratio is required to obtained an unbiased estimate of compressional sound speed in the bottom with a $3 \mathrm{~m} \mathrm{~s}^{-1}$ standard deviation; however, even with low signal to noise ratio, the estimation error remains bounded and (2) in the case of a multi-layer bottom, the scheme produces a single depthaverage compressional sound speed. The inversion scheme is applied on experimental data. The results are fully consistent with a core sample measured around the receiving hydrophone.
\end{abstract}

(C) 2012 Acoustical Society of America. [DOI: 10.1121/1.3672688]

PACS number(s): 43.30.Pc, 43.30.Wi, 43.30.Bp, 43.60.Pt [AIT] Pages: 1999-2010

\section{INTRODUCTION}

The objective of geoacoustic inversion is to characterize the ocean bottom by estimating key parameters such as compressional speed and attenuation, the number of sediment layers, density, etc. Most techniques rely upon the inversion of active emission propagating between a known source and a distant receiving system. Two main types of methods have been proposed to work with emissions of several hundred Hertz: matched field processing (MFP) methods, ${ }^{1}$ which exploit the spatial diversity of the channel's response and matched impulse response (MIR) methods, ${ }^{2}$ which explore the frequency diversity. For emissions below a few hundred Hertz, some of the existing methods are based on the dispersion phenomenon. The underlying idea is to apply signal processing tools to extract the key parameters that depend on the dispersion pattern of the acoustic signal, and then to perform the inversion. ${ }^{3-6}$

\footnotetext{
a) Author to whom correspondence should be addressed. Electronic mail: cedric.gervaise@gipsa-lab.grenoble-inp.fr
}

Active techniques generally require powerful and repetitive emissions which have two major drawbacks. For military purposes, they do not apply in the concepts of covert naval operations. For ecological applications, they are potentially harmful for marine mammals ${ }^{7,8}$ and their operational use is expected to be more and more questionable and subject to mitigation rules in particular in the vicinity of ecologically sensitive areas (e.g., as marine protected areas). To overcome these drawbacks, there is a need to develop passive schemes of geoacoustic inversion which is a basic motivation of this work.

Sound is ubiquitous in the ocean. Ship noise and marine mammal calls can be recorded over great distances, and surface noise is omnipresent. ${ }^{9}$ Consequently, these signals are excellent candidates to perform passive inversion in shallow water. Preliminary results have been obtained for bottom and water column inversions. ${ }^{10-12}$ Surface noise has been particularly well studied, allowing the development of experimental systems ${ }^{10,13}$ For example, a recent technique referred to as passive fathometer, allows to image seabed layers using oceanic ambiant noise as the sound source and a vertical line array as the receivers. ${ }^{14,15}$ Marine mammal 
vocalization are only sparsely represented in the field of geoacoustic inversion. ${ }^{11,12,16}$

In this paper, we focus on methods using moving ships as sources of opportunity. Most methods exploiting the radiated noise from a moving ship are based on the inversion of cross spectral density matrices (CSDM), which require the use of a receiving array (horizontal or vertical). CSDM are often computed over a few narrow frequency bands characterizing ship noise. ${ }^{17-21}$ Sometimes, the CSDM are averaged over several frequency bandwidths. ${ }^{22,23}$ However, the CSDM does not exploit the whole broadband nature of the noise radiated by a ship and the range aperture created by its movement.

The broadband noise radiated by a moving ship creates a characteristic signal when recorded on a single receiver. In the time-frequency domain, the received signal presents an interference pattern, which is sometimes referred to as striations or interference fringes. ${ }^{18,24-27}$ These striations are created by the combination of three important factors: the source is mobile, broadband and radiating in a shallow water environment.

In 1999, D'Spain and Kuperman ${ }^{28}$ introduced the waveguide invariant to explain the striations. To validate the model, they compared predicted and measured interference patterns obtained from a towed active source (pseudo random noise with a flat spectrum between $75 \mathrm{~Hz}$ and $150 \mathrm{~Hz}$ ) in shallow waters (150 -m depth) off the coast of San Diego. An excellent match between prediction and measurements validated the waveguide invariant modeling. In a more recent paper from 2004, Heaney ${ }^{24}$ proposed a geoacoustic inversion scheme based on interference patterns. Experiments were conducted in a 100-m-deep shallow water environment. Ship noise was measured on a horizontal line array. Measurements were pre-processed by a beamformer to improve the signal to noise ratio (SNR). For a discrete set of ranges and frequencies, the author extracted three channel features from the measurements in a range-frequency representation: time spread, waveguide invariant and transmission loss slope. Then, he inverted these features to estimate the two parameters of the Hamilton-Bachman sediment parametrization $^{29}$ Since Heaney's work, more recent publications focus on estimating the same striation characteristics, which can be used as observable either for source ranging or geoacoustic inversion. Several methods allowing striations estimation have been proposed including Hough transform, ${ }^{25}$ striations based beamforming, ${ }^{26}$ and multi-scale filters. ${ }^{27}$

The geoacoustic inversion approach proposed in this paper exploits both the spatial and frequency diversity of the acoustic signal radiated by a moving ship. Considering a range independent waveguide, it proposes a new way to exploit striations in the spectrogram of sounds radiated by a passing ship using the normal mode theory. The periodic behavior of these striations (versus range) is used to estimate a collection (versus frequency) of differences of radial wavenumbers between each couple of propagating modes. Easily tractable from the measurement, this collection called the measured relative dispersion curves (referred to as M RDC hereafter) is used as an observable. Inversion is carried out by estimating bottom geoacoustic parameters which minimize the discrepancy between predictive relative dispersion curves (referred to as P RDC hereafter) and M RDC.

The paper is organized as follows. Section II presents at-sea experiments used to validate the method. Section III is dedicated to the forward modeling stage, it establishes a relationship between the received signal, the RDC and the environmental properties. Section IV presents the inversion method and describes how the RDC are obtained and inverted. Finally, in Sec. V, the inversion method is applied both on simulated and real data. The last two sections present, respectively, discussion and conclusion.

\section{THE MOVEBOAT2006 EXPERIMENTAL SETUP}

This section presents the experiment used to validate the inversion scheme. Data were recorded within the scope of MOVEBOAT2006, a multi-disciplinary and collaborative project. The study area was a $15 \mathrm{~m}$-deep channel located near Vilanova i la Geltru, Spain (Lat: $41^{\circ} 10.8227$ N, Long: $1^{\circ} 43.1204 \mathrm{E}$ ) on a shipping lane between a fish farm and the local harbor (Fig. 1).

During the experiment, sea surface temperature was recorded by the probe of the supply ship with an uncertainty of $0.15^{\circ} \mathrm{C}$. Due to the little temperature variability and the small depth of the water column, water sound speed was assumed to be constant at $1520 \pm 0.75 \mathrm{~m} \mathrm{~s}^{-1}$. The upper part of the bottom structure was known thanks to a core sample collected less than $200 \mathrm{~m}$ from the hydrophone position (project EUMARSIN, measuring id: GC-83-2/TR-417 $7^{30}$ ). The core sample was $50 \mathrm{~cm}$ long and consisted exclusively of sand. The geoacoustic properties of sand have been described by Hamilton. ${ }^{29}$ For our analyses, we assume that this sand layer constituted a semi infinite bottom (see Sec. V B).

Together, the bottom structure and the channel properties represent our a priori knowledge of the channel. This information have to be considered as purely qualitative.

The receiver was a pre-amplified B\&K8101 calibrated hydrophone (low noise custom preamplifier) deployed from an anchored station. The hydrophone depth was set by the operator between 6 and $12 \mathrm{~m}$. The recorded signal passed through an $A / D$ converter with a $2560 \mathrm{~Hz}$ sampling rate and a 16 bit resolution. The noise of a cooperative trawler called Domingo (a $15 \mathrm{~m}$-long vessel, with $2 \times 700$ HP engines) was recorded. As presented in Fig. 1, Domingo performed several $4 \mathrm{~km}$ transects (monitored via a GPS) with a closest point of approach (CPA) distance between 10 and $500 \mathrm{~m}$. When another ship transited on a straight line in the experimental area, the Domingo was asked to stop her engines in order to include opportunistic transects in the analysis. A total of 29 recordings (duration: $20 \mathrm{~min}$ each, 14 transects of Domingo, 14 transects of opportunistic trawlers, 1 yacht) were acquired. In this paper, we will focus on the results of only two tracks of the Domingo. These two tracks, the only ones parallel to the shore line without other audible ships in the neighborhood of the hydrophone, complies with our assumption of a range independent waveguide. Tracks with varying bathymetry will be used in a near future to adapt our method to range-dependent environments. For the inversion analysis, the position of the Domingo is assumed to be 


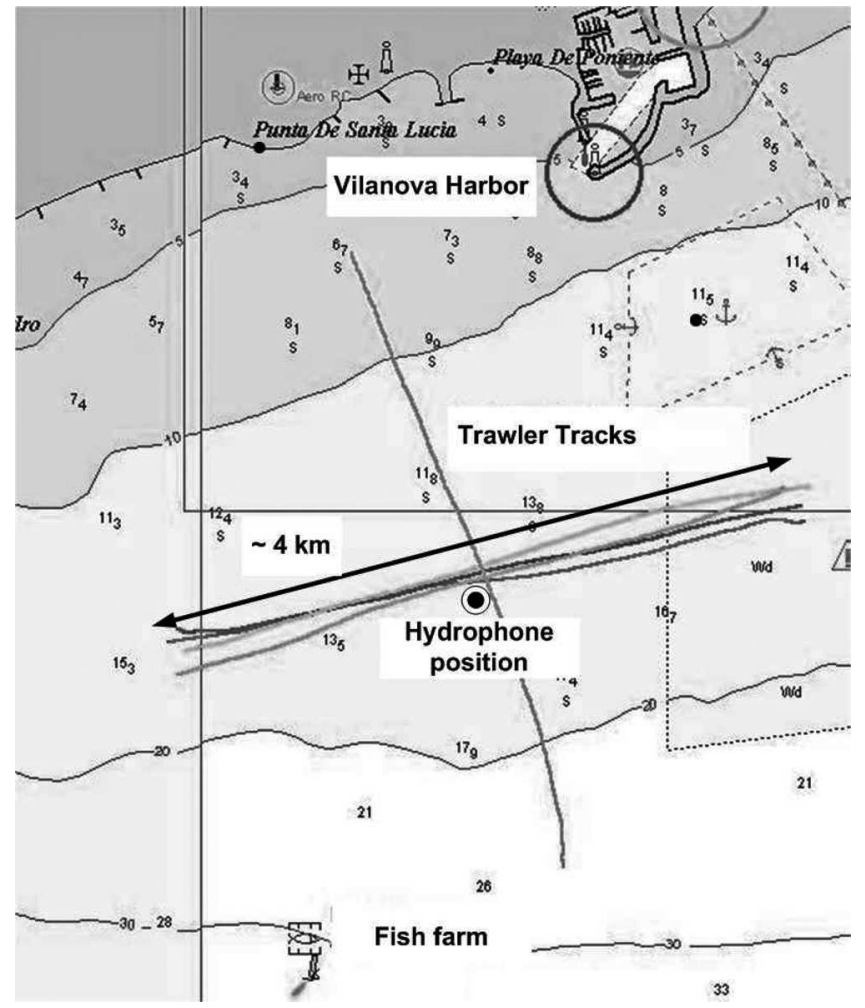

FIG. 1. MOVEBOAT2006 chart presenting Vilanova i la Geltru harbor, isobath line, hydrophone's position, fish farm and typical tracks (parallel to the shoreline above the 15 meter isobath) of cooperative DOMIGO trawler.

unknown, and GPS positions are only for control purposes. Power spectral densities (PSD) of ship-radiated sounds and ambient noise are estimated following the methods described by Vallez et al. ${ }^{31}$ A comparison between ship and noise levels between $200 \mathrm{~Hz}$ and $1000 \mathrm{~Hz}$ reveals that ship noise prevails over ambient noises for ranges up to $3 \mathrm{~km}$.

\section{FORWARD MODELING}

\section{A. Propagation and source movement}

Although ship noise may exhibit discernible contributions $^{32}$ from several hertz to $10 \mathrm{kHz}$ until several kilometers apart, our inversion scheme focuses on the [50-500 Hz] bandwidth. In this bandwidth, for shallow waters environments, propagation is driven by refraction in the water column and reflexions at the interfaces. Striations may be explained both by ray path and normal mode theory. ${ }^{33}$ In this paper, we choose the normal mode theory as the best way to link our observables with bottom parameters that have to be estimated.

In a range-independent environment, the transfer function between the source and the receiver is ${ }^{34}$

$$
H(f) \simeq Q \sum_{m=1}^{N} g_{m}\left(z_{s}\right) g_{m}\left(z_{r}\right) \frac{e^{-j k_{m}(f) r}}{\sqrt{k_{m}(f) r}}
$$

where $g_{m}(z)$ represents the modal function of index $m, k_{m}(f)$ is the radial wavenumber of index $m$ at frequency $f, z_{s}$, and $z_{r}$ are, respectively, the source and receiver depth, $r$ is the radial distance, $N$ is the number of propagating modes and
$Q=\frac{e^{j \pi / 4}}{\sqrt{8 \pi \rho\left(z_{s}\right)}}$ represents a constant factor with $\rho\left(z_{s}\right)$ being the water density at the depth of the source. The radial wavenumbers $k_{m}(f)$ are characteristic features of the propagation properties between the emitter and the receiver. Indeed, the radial wavenumber is a function of the index $m$ and frequency $f$ and the modal propagation is dispersive. The curves $k_{m}(f)$ are called dispersion curves.

Equation (1) describes a linear time-invariant system between the transmitter and the receiver. When the source moves within the channel, it becomes a linear time-varying system. A moving source emitting at a single frequency $f_{0}$ will induce a harmonic response, which excites other frequencies than $f_{0}$ because of the Doppler effect. ${ }^{35}$ The source trajectory can be described using the source/receiver range $r\left(t_{e}\right)$ for a given emission time $t_{e}$. The harmonic timedependent response of the waveguide becomes ${ }^{36}$

$$
h(t, f) \simeq \sqrt{2 \pi} \sum_{m=1}^{N} g_{m}\left(z_{S}\right) g_{m}\left(z_{r}\right) \frac{e^{-j k_{m}(f) r\left(t_{e}\right)}}{\sqrt{k_{m}(f) r\left(t_{e}\right)}}
$$

where $t_{e}$ is the emission (or delayed) time and $t$ is the reception (or contemporary) time the term $\exp \left(-j k_{m}(f) r\left(t_{e}\right)\right)$ explains the Doppler modulation of the emitted monochromatic signal $\exp (-j 2 \pi f t)$. Note that if the source is moving slowly, its movement during the propagation time is negligible. Consequently, the source/receiver range does not change during propagation and $r\left(t_{e}\right)=r(t)$. This classical assumption will be used in the following sections.

For a broadband ship noise of Source Level (SL) $\gamma_{\mathrm{e}}(f)$ (in unit of $\mu P a^{2} @ 1 \mathrm{~m} / \mathrm{Hz}$ ), the sound Received Level (denoted RL hereafter, in unit of $\mu \mathrm{Pa}^{2} / \mathrm{Hz} I(t, f)$ ) is

$$
I(t, f)=|h(t, f)|^{2} \gamma_{e}(f)
$$

Based on this equation, we develop a simulator that allows us to compute the received signal (in the time domain) for any radiated signal in a range-independent medium. The modal code ORCA $^{37}$ was used as a core for the simulation of sound propagation.

\section{B. Channel propagation features}

Recording the radiated noise of a ship moving along a useful track [for which the range along $t$ is denoted $r(t)$ hereafter] over a period $\left[t_{\min }, t_{\max }\right]$ (denoted $\mathrm{T}$ hereafter) in a bandwidth $\left[f_{\min }, f_{\max }\right]$ (denoted $\mathrm{B}$ hereafter) enables to map the acoustic response of the channel in the frequencywavenumber domain.

Assuming that the emitted noise is a unknown random process measured by a single sensor, correlation with the emitted signal or between measurements from several sensors ${ }^{17-23}$ can not be used to pre-process the data and extract some observables. To cope with these limitations, we first compute the received level of the measurements. We then obtain observables quantities from the processing of the RL. In that sense, evaluation of the square modulus of received pressure in a time-frequency domain may be seen 
as an incoherent pre-processing of the data. The RL versus time and frequency is given by ${ }^{34}$

$$
I(t, f)=\frac{\gamma_{e}(f)}{r(t)}\left(\sum_{n} A_{n}^{2}+2 \sum_{n, m} A_{n} A_{m} \cos \left[\Delta k_{m, n} r(t)\right]\right),
$$

where $\Delta k_{m, n}=k_{m}-k_{n}$ and $A_{m}=\left[g_{m}\left(z_{s}\right) g_{m}\left(z_{r}\right)\right] / \sqrt{k_{m}}$. These latter two quantities only depend on the environmental parameters and frequency, they are constant in terms of time and range. Knowing $r(t), I(t, f)$ can be easily translated into range-frequency $\mathrm{RL}$ (in the unit of $\mu \mathrm{Pa}^{2} / \mathrm{Hz}$ ) $I(r, f)$ :

$$
I(r, f)=\gamma_{e}(f)\left(\sum_{n} A_{n}^{2}+2 \sum_{n, m} A_{n} A_{m} \cos \left[\Delta k_{m, n} r\right]\right) .
$$

One important component of Eq. (5) are the cos terms. They explain the interference striation pattern in a rangefrequency RL representation. For a given (temporal) frequency $\mathrm{f}_{0}$, the spatial frequency of interferences between modes $m$ and $n$ is given by $\Delta k_{m, n}\left(f_{0}\right) / 2 \pi$. This propagation feature is easily accessible by translating $I(r, f)$ into the wavenumber-frequency domain. It is done taking the one dimensional Fourier transform along $r\left(F T_{r}\right)$ of $I(r, f)$

$$
\begin{aligned}
I(k, f) & =F T_{r}[I(r, f)] \\
& =2 \gamma_{e}(f) \sum_{n, m} A_{n} A_{m} F T_{r}\left[\cos \left(\Delta k_{m, n}(f) r\right)\right] \\
& =2 \gamma_{e}(f) \sum_{n, m} A_{n} A_{m} \delta\left(k-\Delta k_{m, n}(f)\right),
\end{aligned}
$$

where $\delta$ is the Dirac delta function. Note that the mean value of $I(r, f)$ has been subtracted before computing the $F T_{\mathrm{r}}$, so that resulting $I(k, f)$ is not clouded by a high central value $I(0,0)$.

Let us denote $\left(\begin{array}{l}N \\ 2\end{array}\right)$ the number of combinations of 2 different modes chosen among $\mathrm{N}$ propagative modes:

$$
\left(\begin{array}{c}
N \\
2
\end{array}\right)=\frac{N !}{(N-2) ! 2 !}
$$

At frequency $f_{0}$, if $N$ propagative modes exist, there are $\left(\begin{array}{c}N \\ 2\end{array}\right)$ cos components in the map $I\left(k, f_{0}\right)$. Each component corresponds to (see Fig. 2): (1) an interference between modes $n$ and $m$ and (2) a local maximum in the map $I(k, f)$ at location $\left(\Delta k_{m, n}\left(f_{0}\right), f_{0}\right)$.

Because the radial wavenumber $k_{m}$ depends on frequency $f$, phase and group velocities vary with frequency.

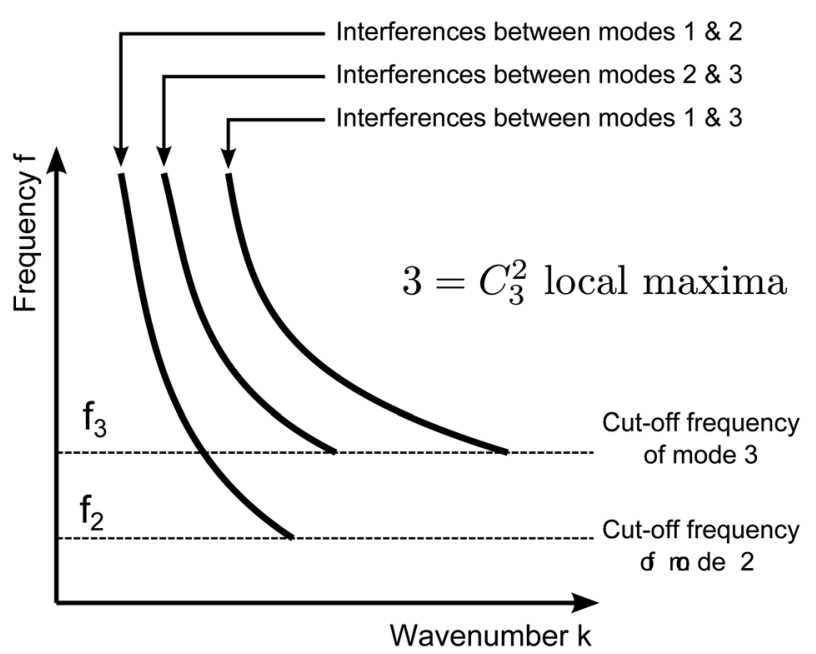

FIG. 2. Schematic RDC curves in the $(k, f)$ plane. For frequencies lower than $f_{2}$ only mode 1 propagates, no interference exists. For frequencies in $\left[f_{2}, f_{3}\right]$ modes 1 and 2 propagate and interfere together to create a single curve between $f_{1}$ and $f_{2}$ along $k_{2}(f)-k_{1}(f)$. For frequencies higher than $f_{3}$, modes 1,2 , and 3 propagate ant interfere together to created three relative dispersion curves located along $k_{2}(f)-k_{1}(f), k_{3}(f)-k_{1}(f)$, and $k_{3}(f)-k_{2}(f)$.

The propagation in the channel between the source and the receiver is referred to as dispersive and $k_{m}(f)$ is the dispersion curve of mode $m$. When dealing with RL (in the unit of $\mu \mathrm{Pa}^{2} / \mathrm{Hz}$ )) rather than pressure, dispersion is seen through the dependency $\Delta k_{m, n}$ versus the frequency $f$. The quantity $\Delta k_{m, n}(f)$ can be referred to as a relative dispersion curve between propagative modes $m$ and $n$. A full overview of the dispersion properties of a channel is drawn by assembling the relative dispersion curve of each of the $\left(\begin{array}{c}N \\ 2\end{array}\right)$ couples of indexes $(n, m)$ (see Fig. 2) to obtain the RDC.

RDC summarizes the acoustical behavior of a channel through a mobile wide band input and a single hydrophone output scenario. When simulating a real context, finite range will limit the resolution of the $I(k, f)$ map and noise will add a random component to $I(k, f)$. It is important to notice that because of the incoherent processing, the wavenumberfrequency domain cannot provide straightforward information about wavenumbers $k_{n}$. It only allows to obtain information about wavenumber differences $\Delta k_{m, n}$, this will have some consequences on the capability of our inversion scheme to discriminate sub-bottom layers (see Sec. V B).

\section{INVERSION METHOD}

To exploit information from the interference pattern created by ship noise, we designed an inversion scheme. A schematic representation of this algorithm is shown in Fig. 3.

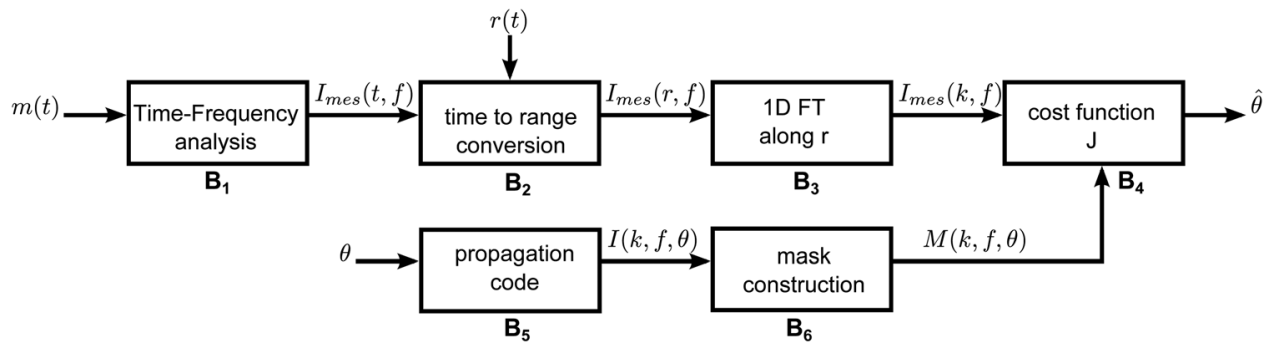

FIG. 3. Inversion scheme diagram. 
The first step of the method is devoted to the measurements. The sound radiated by a passing ship along a straight line transect is measured by a bottom-moored hydrophone to output measurements $m(t)$ during the time period $T$ and within the bandwidth $B$. The time period is chosen so that the ship is far enough to avoid evanescent modes. The spectrogram $^{38}$ of $m(t)$ is computed to map $m(t)$ in the timefrequency space (Bloc $B_{1}$ in Fig. 3), and allows to obtain $I_{\text {mes }}(t, f)$. Special attention has to be drawn to the management of long measurements (duration: $1 \mathrm{~h}$, sampling frequency $>2 \mathrm{kHz}$ ). Translation from $I_{\text {mes }}(t, f)$ to $I_{\text {mes }}(r, f)$ can be easily obtained by an uniform resampling of $r(t)$ (Bloc $B_{2}$ in Fig. 3). Boat position $r(t)$ can be gathered from a position tracking system (e.g., Automatic Identification System, AIS $^{39}$ or Global Positioning System, GPS). In the absence of tracking system, they can be estimated through Target Motion Analysis, ${ }^{40}$ which exploits the Doppler modulation of powerful frequency lines at frequency $f_{0}$ and under the mild assumption that ship motion is uniform and follows a straight line. The measured law of instantaneous frequency around $f_{0}$ is used to estimate ${ }^{41,42}$ the ship's speed ( $v$ in the unit of $\mathrm{m} \mathrm{s}^{-1}$ ) and the time and distance of the closest point of approach ( $t_{\text {cpa }}$ in the unit of $\mathrm{s}, d_{\text {cpa }}$ in the unit of $\mathrm{m}$ ). The TMA algorithm is used for the MOVEBOAT2006 data in order to determine the Domingo's trajectories. GPS logged on the Domingo trajectory as a reference and TMA is applied to estimate the trajectory with acoustics thanks to a frequency line around 600 Hertz. A very good fit holds on between GPS trajectory and trajectory recovered with acoustics. Wavenumber-frequency intensity $I_{\text {mes }}(k, f)$ is obtained from $I_{\text {mes }}(r, f)$ by computing a Fourier transform of $I_{\text {mes }}(r, f)$ along $r$ (see bloc $\mathrm{B}_{2}$ in Fig. 3). At the end of this step, the intensity of the received signal $I_{\text {mes }}(k, f)$ represents the observable that can be used to estimate the channel's properties. In this paper, we will focus on the bottom properties (compressional sound speed, density and attenuation of a semi-infinite half space) assuming that those of the water column are known. The main idea of the inversion algorithm is to find an environment, parameterized by a set of geoacoustic parameters $\boldsymbol{\theta}$, with dispersion curves that match the local maxima of $I_{\text {mes }}(k, f)$ (see blocs $B_{4}, B_{5}$, and $B_{6}$ in Fig. 3).

For a given $\boldsymbol{\theta}$, the $I(k, f, \boldsymbol{\theta})$ replica can be computed through a modal propagation code. To quantify the match between $I_{\text {mes }}(k, f)$ and $I(k, f, \boldsymbol{\theta})$, an objective function $J$ is defined as the amount of measured intensity integrated along each component of the $\{R D C(\boldsymbol{\theta})\}$ :

$$
J(\boldsymbol{\theta})=\int_{f} \int_{k} \mathrm{I}_{\mathrm{mes}}(k, f) M(k, f, \boldsymbol{\theta}) d k d f .
$$

In this equation, $M(k, f, \boldsymbol{\theta})$ is a masking function corresponding to the $\{R D C(\boldsymbol{\theta})\}$ curves spread by a factor $2 \pi /\left(R_{\max }\right.$ $-R_{\min }$ ) (see Fig. 4):

$$
\begin{aligned}
M(k, f, \boldsymbol{\theta}) & =1 \text { if } k \in\left[\Delta k_{m, n}(f, \boldsymbol{\theta}) \pm \frac{2 \pi}{R_{\max }-R_{\min }}\right] \\
& =0 \text { anywhere else. }
\end{aligned}
$$

The quantities $R_{\max }$ and $R_{\min }$ are respectively the maximum and the minimum range considered in the ship trajectory;

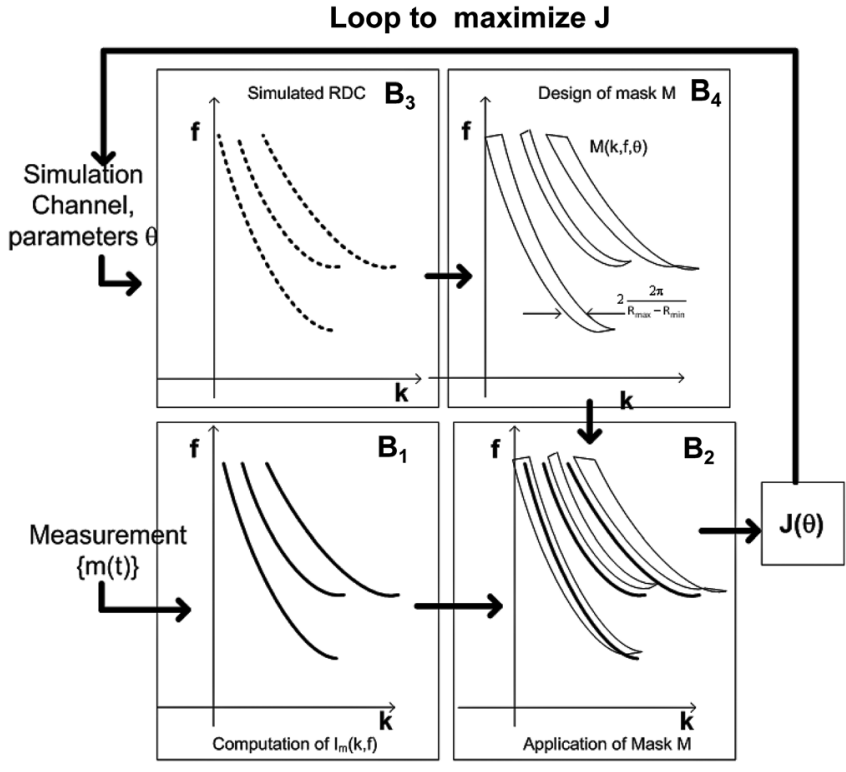

FIG. 4. Flowchart to define and optimize the objective function J. Measurement are processed in box $B_{1}$ to compute $I_{\text {mes }}(k, f)$. In the box $B_{2}$, the map $I_{\text {mes }}(k, f)$ is matched to a synthetic binary map $M(k, f, \theta)$ obtained from simulation. Applied on $I_{\text {mes }}(k, f)$ the goal of $M(k, f \theta)$ is to extract the power contained by the measurement around some simulated RDC. To do so, for a given $\theta$ the simulated RDC are computed in box $B_{3}$, RDC appear to have an ideal infinite resolution in the $(k, f)$ plane. To account for the bounded range $R_{\max }-R_{\min }$ of the measurements, each RDC is broaden by the expected resolution of $I_{m}(k, f)$ [i.e., $2 \pi /\left(R_{\max }-R_{\min }\right)$ ] to form a binary masking map in the $(k, f)$ plane with one around the simulated RDC and zero elsewhere. An optimization procedure is applied on $\theta$ to optimize the amount of power of $I_{m}(k, f)$ contained in the mask $M(k, f, \theta)$.

$2 \pi /\left(R_{\max }-R_{\min }\right)$ is the wavenumber resolution of $I_{\text {mes }}(k, f)$ after application of the Fourier transform along $r$.

Finally, the optimal set of parameters $\hat{\boldsymbol{\theta}}$ maximizes $J$ :

$$
\hat{\boldsymbol{\theta}}=\underset{\boldsymbol{\theta}}{\arg \max }[J(\boldsymbol{\theta})]
$$

\section{APPLICATION IN A VERY SHALLOW WATER ENVIRONMENT}

\section{A. Signal to noise ratio estimation}

In a real environment, the received signal is corrupted with noise. The signal to noise ratio (SNR) quantifies the relative level of the useful signal versus noise. This section gives a precise definition of SNR and a procedure to compute it on simulated and real data.

Let us suppose that the current experiment implies a single ship radiating a source level $\gamma_{e}(f)$ (in the unit of $\mu \mathrm{Pa}^{2} /$ Hz@1 m) embedded in background noise created by other distant ships, sea surface agitation or oceanic turbulences with level $\gamma_{b}(f)$ (in the unit of $\mu \mathrm{Pa}^{2} / \mathrm{Hz}$ ). The measures for a broadband source with a bandwidth of $\left[f_{1}-f_{2}\right]$ can be derived from Eq. (3) and is given by Eq. (11), where $b(t)$ is the background noise. The corresponding intensity in the range-frequency domain for a single frequency is obtained from Eq. (5) by adding the noise spectrum following Eq. (12),

$$
m[r(t)]=\int_{f_{1}}^{f_{2}} h(t, f) \sqrt{\gamma_{e}(f)} e^{2 j \pi f t} d f+b(t),
$$




$$
I_{m}(r, f)=I_{0}(r, f)+\gamma_{b}(f),
$$

with $I_{0}(r, f)$ the noiseless range-frequency intensity given by Eq. (5).

Considering a finite number of frequencies $N_{f}$ in the bandwidth $\left[f_{1}-f_{2}\right]$ and a finite number of ranges $N_{r}$ for a moving ship performing a track in the interval $\left[r_{1}, r_{2}\right]$, the SNR can be computed as follows:

$$
\mathrm{SNR}=\frac{\sum_{N_{r}} \sum_{N_{f}} I_{0}(r, f)}{N_{r} \sum_{N_{f}} \gamma_{b}(f)} .
$$

Equation (13) is only tractable with simulated data, where both noise $\gamma_{b}(f)$ and theoretical measurements without noise $I_{0}(r, f)$ are generated separately. Equation (13) is not tractable for real data and an alternative formula has to be identified. As the Fourier transform along $r$ conserves the energy, SNR can be estimated from $I_{\text {mes }}(k, f)$ by taking into account the fact that the useful signal $\left(I_{0}(k, f)\right)$ is concentrated around the RDC and that noise is spread everywhere on the $(k, r)$ plane. Let $M\left(k, f, \theta_{\text {opt }}\right)$ the mask for optimal environment parameters $\theta_{\mathrm{opt}}$, then SNR can be estimated from real data by

$$
\mathrm{SNR}=\frac{\int_{k} \int_{f} I_{\mathrm{mes}}(k, f) M\left(k, f, \theta_{\mathrm{opt}}\right) d k d f}{\int_{k} \int_{f} I_{\mathrm{mes}}(k, f)\left(1-M\left(k, f, \theta_{\mathrm{opt}}\right)\right)} .
$$

SNR estimation from real data may be facilitated if ambient noise is stationary and recorded before or after the ship's track. In MOVEBOAT2006, this was not possible since noise was not stationary (at the scale of $1 \mathrm{~h}$ ) due to the activity in the harbor of Vilanova I la Geltru (see Fig. 1). Therefore, SNR was estimated using Eq. (13).

\section{B. Simulations}

This section evaluates the performance and behavior of our inversion scheme. Simulations are performed in a "realistic synthetic" scenario with parameters corresponding to those of the MOVEBOAT2006 in situ experiment. A range interval $R=[200 \mathrm{~m}, 2 \mathrm{~km}]$ and frequency bandwidth $B=[150 \mathrm{~Hz}, 500$ $\mathrm{Hz}]$ were considered. To take into account the fact that the structure (number of layers) of the studied environment is often unknown, we define the "true waveguide" as the channel structure that is used to generate the measurements, and the "guessed waveguide" as the channel structure that is used to compute the replica. Note that true and guessed waveguides are not necessarily parameterized by the same number of parameters.

Two studies are presented in this section. The first one quantifies the impact of noise on estimation accuracy, and the second one evaluates the impact of a structure mismatch between guessed waveguide and true waveguide. In the following, the guessed waveguide is always a Pekeris waveguide, where

(1) water sound speed and water depth are supposed to be known (isovelocity water column, $\mathrm{D}=20 \mathrm{~m}$, $c_{w}=1520 \mathrm{~m} \mathrm{~s}^{-1}$ ),
(2) compressional sound speed $\left(c_{b}\right)$ and density $(\rho)$ of the bottom are assumed to be linked by the Hamilton formula $^{24,29}$ as follows:

$$
\begin{aligned}
& c_{b}=\frac{c_{w}}{1.18-3.4 \Phi+0.0013 \Phi^{2}}, \\
& \rho=\frac{28.85-\Phi}{10.275},
\end{aligned}
$$

where $\Phi$ is the grain size parameter equal to $-\log _{2}(\mu)$ with $\mu$ is the mean grain diameter of the sediment in the unit of $\mathrm{mm}$.

Consequently, optimization of the objective function $J$ is performed only along the compressional sound speed of the bottom.

\section{Study 1: Impact of noise on estimation accuracy}

In this study we investigate the impact of background noise on the estimation accuracy (bias and standard deviation) through Monte Carlo simulations for various SNR. The true waveguide used to generate the measurements is a coarse sandy Pekeris waveguide $\left(c_{b}=1800 \mathrm{~m} \mathrm{~s}^{-1}\right.$, $\left.\rho=1850 \mathrm{~kg} \mathrm{~m}^{-3}, \alpha=0 \mathrm{~dB} / \lambda\right)$. For each SNR value, 100 runs of the inversion scheme were performed with noisy synthetic measurements simulated using Eq. (12) under the assumption of an additive, white, Gaussian noise. Figure 5 presents the average and standard deviation of the estimation of compressional sound speed of the bottom whereas Fig. 6 illustrates a few samples of the objective function for various SNR. Two distinct areas can be observed (Fig. 5).

(1) For SNR lower than $6 \mathrm{~dB}$ (area 1 on Fig. 5), standard deviations are higher than $3 \mathrm{~m} \mathrm{~s}^{-1}$ thus leading to a $99 \%$ confident interval wider than $20 \mathrm{~m} \mathrm{~s}^{-1}$. The compressional sound speed estimate is therefore overestimated.

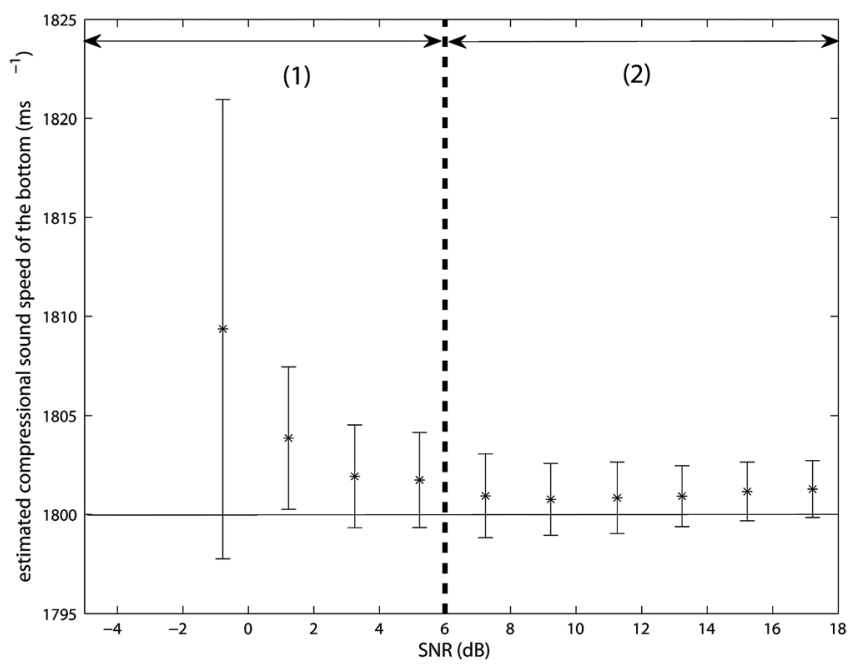

FIG. 5. Accuracy of our inversion scheme versus SNR, mean value and standard deviation of compressional sound speed of the bottom estimates ( $N=100$ runs of independent simulations for each SNR value). For $\mathrm{SNR}<6 \mathrm{~dB}$, estimates are biased, for $\mathrm{SNR}>6 \mathrm{~dB}$ estimates are unbiased and have a standard deviation less than $3 \mathrm{~m} \mathrm{~s}^{-1}$. 
As an example, for $\mathrm{SNR}=-0.7 \mathrm{~dB}$, a positive bias of $10 \mathrm{~m} \mathrm{~s}^{-1}$ appears.

(2) For SNR greater than $6 \mathrm{~dB}$ (area 2 on Fig. 5), standard deviation decreases with SNR and is smaller than $3 \mathrm{~m} \mathrm{~s}^{-1}$ leading to a $99 \%$ confident interval smaller than $20 \mathrm{~m} \mathrm{~s}^{-1}$. In this case, the estimate of the compression sound speed is unbiased.

These differences can be explained by analyzing the cost functions (Fig. 6). The cost function presents a unique global maximum that allows to use a simple method for optimization. The short computational time for the algorithm enables exhaustive exploration of the compressional sound speed estimates comprised between $1700 \mathrm{~m} \mathrm{~s}^{-1}$ and $1900 \mathrm{~m} \mathrm{~s}^{-1}$ with a $1 \mathrm{~m} \mathrm{~s}^{-1}$ resolution. The maximum value of cost function decreases with increasing noise power [from 0.6 for $\mathrm{SNR}=63 \mathrm{~dB}$ to 0.28 for $\mathrm{SNR}=2.50 \mathrm{~dB}$, Fig. 6(a) $]$ and the width of the cost function increases with increasing noise power [Fig. 6(b)]. This may explain the trends of the standard deviations of the compressional sound speed estimates. Furthermore, the cost function is nearly symmetric around its maximum for SNR greater than $5 \mathrm{~dB}$ but is completely asymmetric for SNRs smaller than $5 \mathrm{~dB}$. This explains why the estimate of the compressional sound speed of the bottom is biased for SNRs smaller than $6 \mathrm{~dB}$.

\section{Study 2: Impact of a structure mismatch between guessed waveguide and true waveguide}

This study aims at determining whether the Pekeris waveguide is appropriate to estimate an environment where the bottom is constituted of several stratified layers. In this case, the true waveguide is assumed to be a known water column overlying a two-layers bottom consisting in a coarse sandy sediment layer $\left(c_{b 1}=1800 \mathrm{~m} \mathrm{~s}^{-1}, \rho_{1}=1.85 \mathrm{~g} \mathrm{~cm}^{-3}, \alpha_{1}=0.1 \mathrm{~dB} \lambda^{-1}\right)$ over a rocky half space $\left(c_{b 2}=2000 \mathrm{~m} \mathrm{~s}^{-1}, \rho_{2}=2.05 \mathrm{~g} \mathrm{~cm}^{-3}\right.$, $\left.\alpha_{2}=0.1 \mathrm{~dB} \lambda^{-1}\right)$. The sediment layer thickness varies between a few centimeters to $100 \mathrm{~m}$. The guessed waveguide is still a Pekeris one. No noise is added to the simulation. Figure 7 summarizes the inversion results. Estimation results are consistent with the first layer thickness. For fine sediment layers (area 1 on Fig. 7, thickness smaller than $25 \mathrm{~cm}$ ), the inversion algorithm describes the rocky half space parameters: the upper sediment layer had nearly no effect on modal propagation. Over a certain thickness of the sediment layer (area 3, thickness higher than $6 \mathrm{~m}$ ), the inversion results are the sediment parameters, the effect of the basement on modal propagation can be neglected. For a thickness of the sediment layer between $0.25 \mathrm{~m}$ and $6 \mathrm{~m}$, a transition zone is clearly visible (area 2 on Fig. 7). On this transition zone, the guessed Pekeris layer has a compressional sound speed that is equivalent to the averaged compressional sound speed of the basement and the sediment layers. Although not surprising, this result has to be discussed in more detail. Can the true waveguide be acoustically described through our inversion scheme as a fully equivalent Pekeris waveguide?

To answer this question, we examine the cost function behavior of three true waveguides, one from each area $(1,2$, and 3). The cost functions versus the guessed compressional sound speed of the bottom are illustrated on Fig. 8. Plots (curve shape and maxima) from areas 1 and 3 reflect the behavior of the cost function for a true Pekeris medium. For area 2, the cost function has the same shape as the ones for areas 1 and 3 with approximately the same width but with a lower maximum magnitude ( 0.55 compared to 0.6 , Fig. 5 ). This decrease in the maximum $\mathrm{J}$ value resulting from the mismatch between the structures of true and guessed waveguide is much smaller than the decrease caused by noise (without any structure mismatch) (example when SNR ranges between $+\infty$ and $10 \mathrm{~dB}$, the maximum value decreases from 0.6 to 0.5 , see Fig. 6). This implies that noise has a greater influence on the inversion scheme than a multi-layer environment. As a (a)

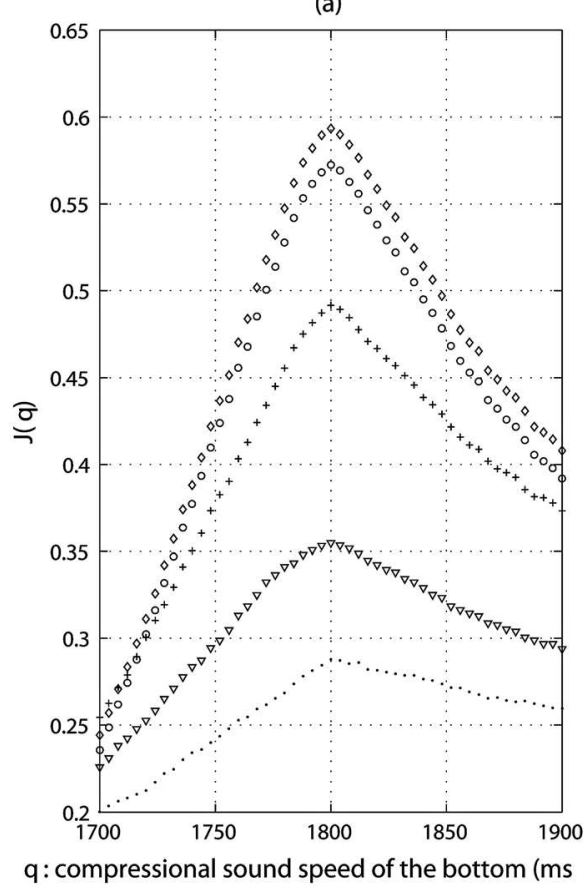

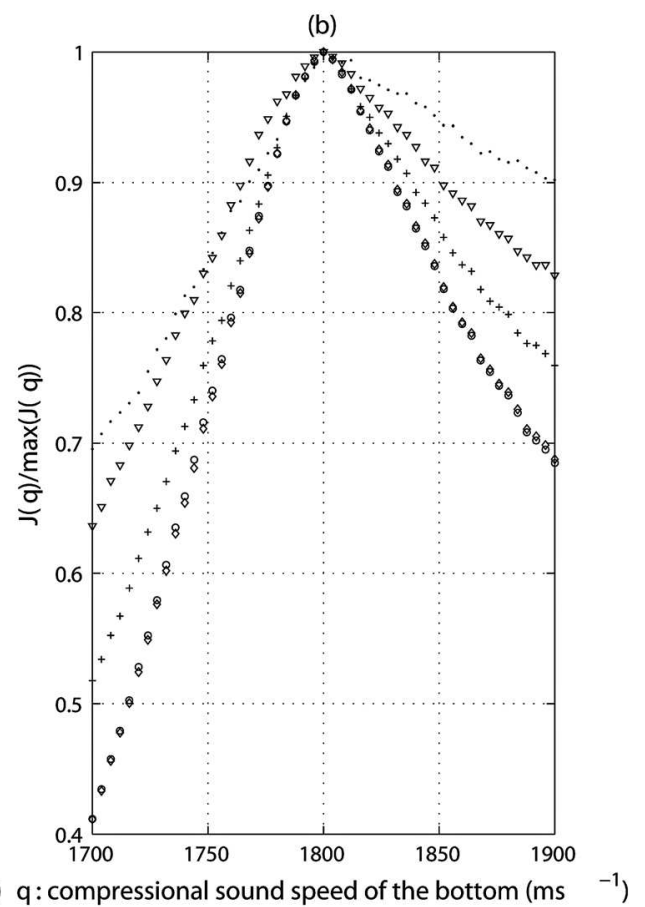

FIG. 6. (a) Shape of objective function J: $\mathrm{SNR}=2.5 \mathrm{~dB}$ (dots); $\mathrm{SNR}$ $=5.58 \mathrm{~dB}$ (triangles); $\mathrm{SNR}=10,70$ $\mathrm{dB} \quad$ (crosses); $\quad \mathrm{SNR}=23.6 \mathrm{~dB}$ (circle); $\mathrm{SNR}=63.5 \mathrm{~dB}$ (diamond); (b) comparison of normalized criterium shape depending on SNR values. The highest the SNR is, the greater the maximum value of the objective function (a) and the narrower the peak around the maximum (b). 


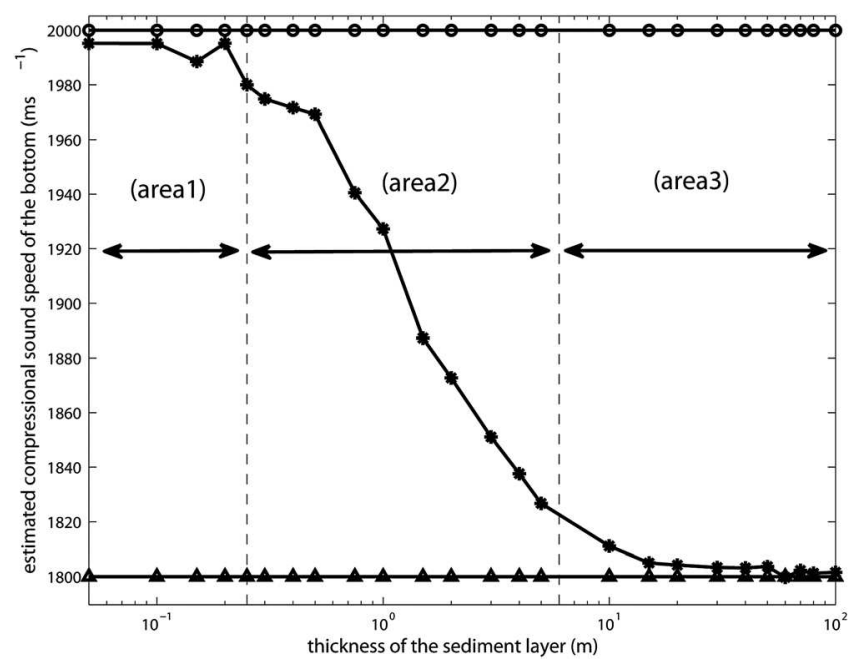

FIG. 7. Estimated compressional sound speed of half space bottom for different thick nesses of the sediment layer (crosses); rock basement compressional sound speed (circles); compressional sound speed of the sediment layer (triangles). For a thin sediment layer (area 1), the estimated compressional sound speed is similar to the basement one; for thick sediment layer (area 3), the estimated compressional sound speed in similar to the sediment layer ones, whereas for a middle thickness (area 2), the estimated compressional sound speed is a depth average between sediment and basement ones.

consequence, a two-layer true waveguide in presence of noise is equivalent to a simulated Pekeris waveguide with an intermediate depth-average compressional sound speed. The transition between zones 2 and 3 occurs at a depth for which the tail of the modal function vanishes. For our scenario used to generate Fig. 7, the longest tail of the modal function measures approximately $6 \mathrm{~m}$ for mode 1 at $150 \mathrm{~Hz}$. It corresponds to a transition depth between zones 2 and 3 equal to 0.5 $\lambda_{\max }=c_{b} / f_{\min }$, where $\lambda_{\max }$ is the maximum wavelength.

\section{Experimental data}

Data obtained from the in situ experiment are presented in Fig. 9(a) and 9(b), these are two tracks collected at different times during the MOVEBOAT2006 experiment on the September 30, 2006 along the $15 \mathrm{~m}$ isobath. Table I summarizes the characteristics of the records and ship trajectory parameters. Vessel speed, $\mathrm{d}_{C P A}$ and $\mathrm{t}_{C P A}$ are estimated using the "Target Motion Analysis" method described in Sec. IV B with a frequency line at $630 \mathrm{~Hz}$ for track 1 and at $628 \mathrm{~Hz}$ for track 2. The SNR (12.8 dB for track 1, $9.8 \mathrm{~dB}$ for track 2$)$ is estimated using Eq. (14).

The white boxes in Figs. 9(a) and 9(b) identify the data selected to perform the in-version To select mode interferences and to avoid tacking into account interferences between paths (like Lloyds mirror interferences), the selected data are chosen carefully. Criteria of selection are firstly that range must be greater than 20 times the water depth (range more than $300 \mathrm{~m}$ for MOVEBOAT2006) and secondly, acoustic wavelength $\lambda$ must be greater than 20 percents of the water depth (frequency less than 500 hertz for MOVEBOAT2006). The received signals in the wavenumber-frequency domain $I_{\text {mes }}(k, f)$ are presented in Figs. 9(c) and 9(d). They represent the input data for the inversion algorithm. According to the conclusion of study 2 of Sec. V A, the guessed waveguide is an equivalent Pekeris waveguide with a bottom sound velocity and a bottom density following the Hamilton formula ${ }^{29}$ [see Eqs. (15) and (16)].

The results of the inversion scheme are $c_{b}$ (track 1$)$ $=1790 \mathrm{~m} \mathrm{~s}^{-1}$ and $c_{b}(\operatorname{track} 2)=1750 \mathrm{~m} \mathrm{~s}^{-1}$ (using the Hamilton relation, the corresponding densities are $\rho=1.84 \mathrm{~g} \mathrm{~cm}^{-3}$ and $\rho=1.80 \mathrm{~g} \mathrm{~cm}^{-3}$ ). These estimates are consistent with a core sample taken near the hydrophone (the core sample $50 \mathrm{~cm}$ long (a)

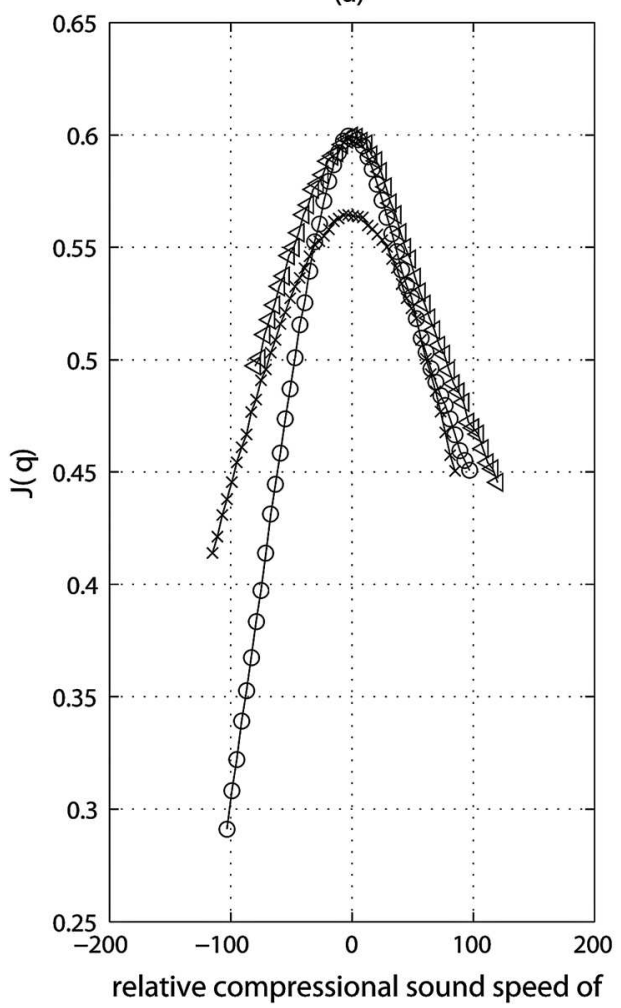

(b)

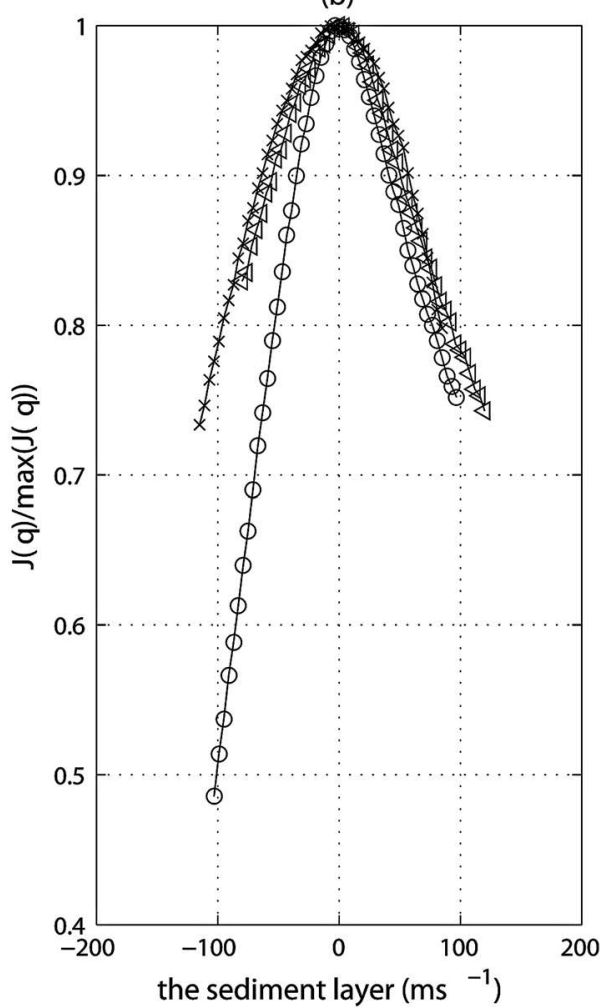

FIG. 8. (a) Shape of the cost function $\mathrm{J}$ depending on the upper layer thickness versus relative compressional sound speed of the guessed sediment layer (i.e., value - value which optimizes J): $10 \mathrm{~m}$ thick sediment layer (circle); $5 \mathrm{~m}$ intermediate sediment layer (crosses); $0.25 \mathrm{~m}$ thin sediment layer (points). (b) Normalized criterion depending on the layer thickness with the same meaning as below; a middle thickness of sediment layer (curves with crosses) creates a small decrease in the maximum value of $\mathrm{J}$ [(a) from 0.6 to $0.56]$, and a small widening of the peak around the maximum (b). 

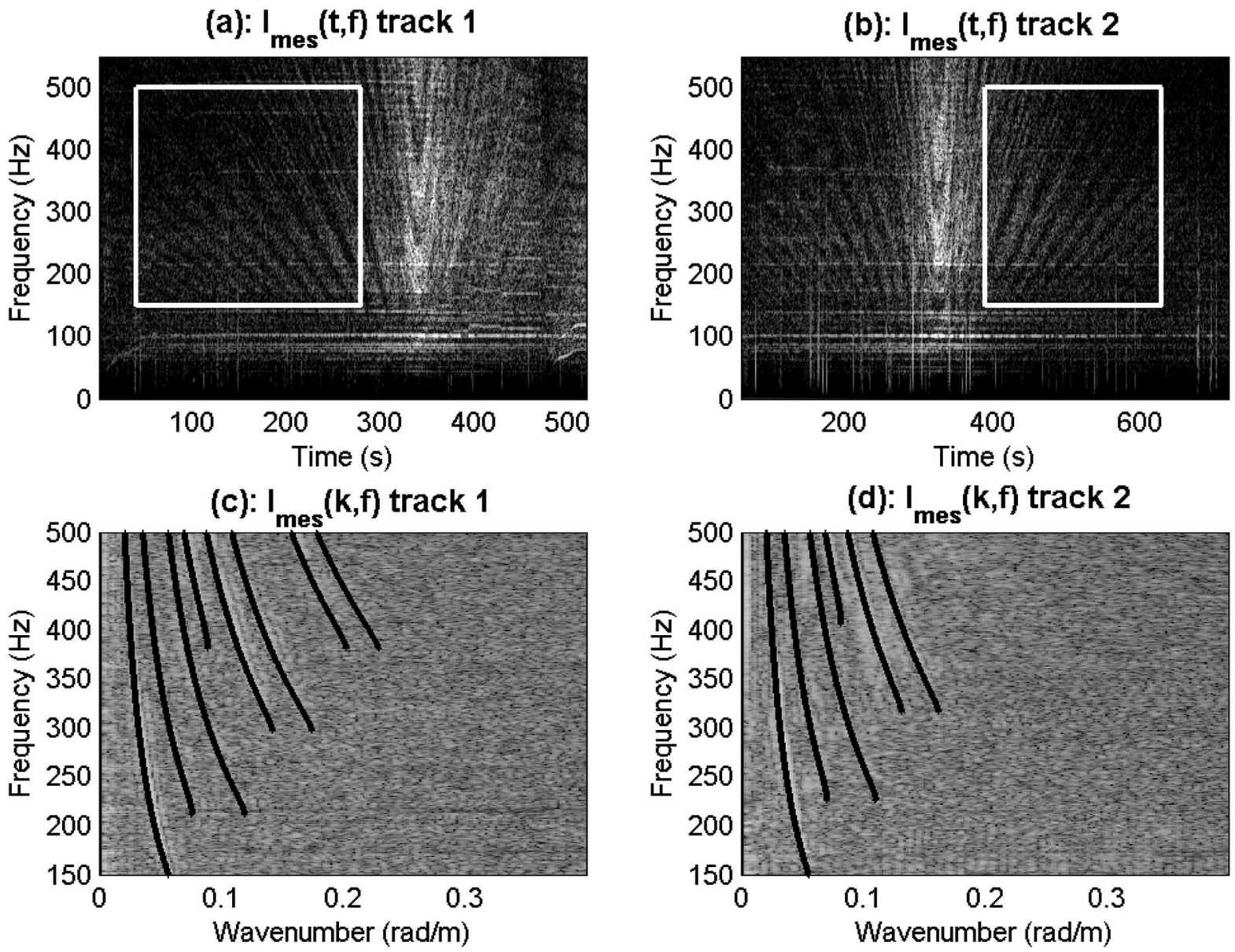

(e): Criterium J, track 1

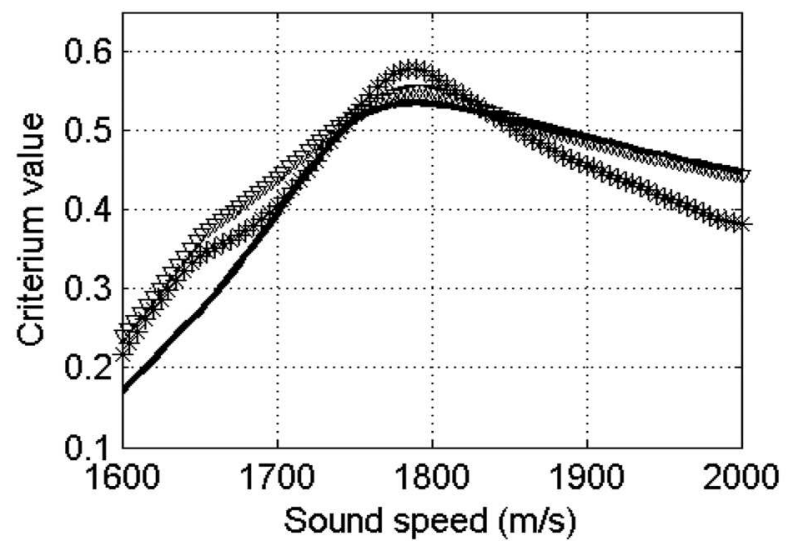

(f): Criterium J, track 2

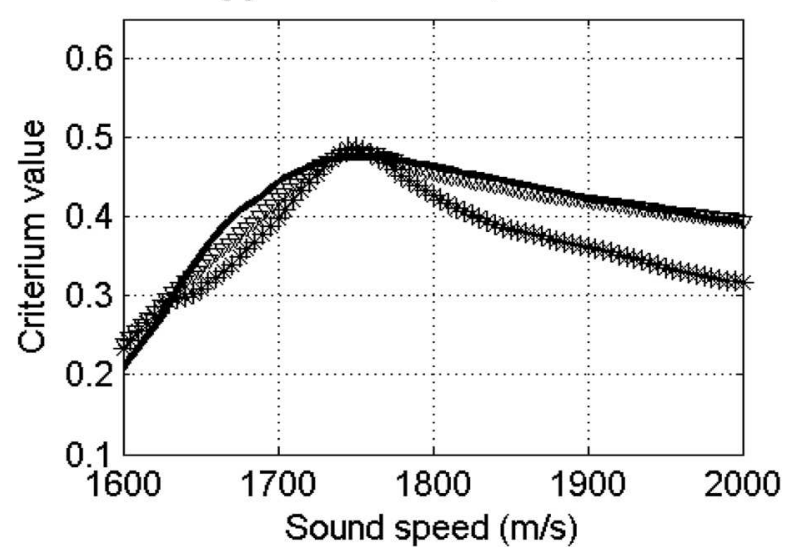

FIG. 9. (a) and (b) $I_{\text {mes }}(t, f)$ for tracks 1 and 2, white boxes identify the data used to compute $I_{\text {mes }}(k, f)$, the ship's range in these boxes is approximately $1500 \mathrm{~m}$ between $300 \mathrm{~m}$ and $1800 \mathrm{~m}$, striations are clearly visible on $I_{\text {mes }}(t, f)$. (c) and (d) $I_{\text {mes }}(k, f)$ for tracks 1 and 2 , and corresponding inverted RDC curves (in black) a good match between local maxima of $I_{m}(k, f)$ and optimal theoretical RDC is visible. (e) Objective functions for track $1:$ real data SNR $=12.5 \mathrm{~dB}$ (continuous line); simulated data with ship's range $=1500 \mathrm{~m}$ and $\mathrm{SNR}=12.5 \mathrm{~dB}$ (crosses); simulated data with ship's range $=750 \mathrm{~m}$ and $\mathrm{SNR}=12.5 \mathrm{~dB}$ (triangles). (f) Objective functions for track 2 : real data $\mathrm{SNR}=9.8 \mathrm{~dB}$ (continuous line); simulated data with ship's range $=1500 \mathrm{~m}$ and $\mathrm{SNR}=9.8 \mathrm{~dB}$ (crosses); simulated data with ship's range $=750 \mathrm{~m}$ and $\mathrm{SNR}=9.8 \mathrm{~dB}$ (triangles).

shows that a homogeneous sandy sediment type $1800 \mathrm{~m} \mathrm{~s}^{-1}$ ). The Objective functions for track 1 and track 2 are presented in Figs. 9(e) and 9(f) and are compared with two simulated curves for SNR close to those obtained during the experiment. The first curve is obtained with a ship range equal to the true one and the second curve with a ship range is half of the true one. The value of the objective functions obtained with true data have the same dynamics than the simulated ones whereas its widths are closer to the one with a simulated ship range equal to half of the true one. This demonstrates that

(1) through our inversion scheme, the true waveguide may nearly be considered as a Pekeris one;

(2) the assumption of a range-independent waveguide from the source to the receiver is valid for tracks along the isobath; 
TABLE I. Recorded data during the MOVEBOAT2006 experiment.

\begin{tabular}{lcc}
\hline \hline Track number & Track 1 & Track 2 \\
\hline Recording time & $11: 45: 00$ & $12: 04: 00$ \\
Duration & $680 \mathrm{~s}$ & $708 \mathrm{~s}$ \\
Range & {$[-2000 \mathrm{~m}, 2000 \mathrm{~m}]$} & {$[-2000 \mathrm{~m}, 2000 \mathrm{~m}]$} \\
Ship speed & $12 \mathrm{kn}$ & $12 \mathrm{kn}$ \\
$\mathrm{d}_{C P A}$ & $60 \mathrm{~m}$ & $80 \mathrm{~m}$ \\
$\mathrm{t}_{C A P}$ & $340 \mathrm{~s}$ & $330 \mathrm{~s}$ \\
SNR & $11.16 \mathrm{~dB}$ & $9.28 \mathrm{~dB}$ \\
\hline \hline
\end{tabular}

(3) the standard deviations (STD) found via Monte Carlo simulation in Sec. V A may hold with the real data $\left(\mathrm{SNR}=12.8 \mathrm{~dB}\right.$ for track 1 so $\mathrm{STD}=3 \mathrm{~m} \mathrm{~s}^{-1}, \mathrm{SNR}$ $=9.80 \mathrm{~dB}$ for track 2 so $\mathrm{STD}=3 \mathrm{~m} \mathrm{~s}^{-1}$ ).

The RDC for the guessed waveguide are compared with their respective $I_{\text {mes }}(k, f)$ in Figs. 9(c) and 9(d). The RDC locations match the local maxima of $I_{\text {mes }}(k, f)$. However, the depth of the hydrophone $(11 \mathrm{~m})$ is near a zero of mode 3 , so each RDC implying mode 3 does not correspond to a local maximum in $I_{\text {mes }}(k, f)$ as it would be the case for other hydrophone depths.

\section{DISCUSSION}

\section{A. Losses and gains of our passive inversion scheme}

The main merit of our passive inversion scheme is to be based upon a simple measurement system and a small amount of a priori information. A single hydrophone and the opportunistic sounds of a ship following an unknown but uniform straight line transect are the minimum requirement. To adapt to this minimum requirements, an incoherent process has to be applied that induces some losses of information. The data used for inversion are represented by the intensity (without phase) in a relative wavenumber (without absolute wavenumber reference) and frequency space. Moreover, we chose to use the far enough part of the ship's track in order to select only the propagative modes to estimate the RDC to be inverted. In the sequel, we restrict our exploration of the bottom only to the weak grazing angles. These information gaps are the reasons why any true multi-layer waveguide can only be represented by an equivalent depthaveraged Pekeris waveguide when computing our inversion scheme. As soon as we deal with low frequency ship noise, we may be faced with a noisy environment with contributions from others ships. Many works on ship noise striations rely on the measurement of the waveguide invariant (the rate of the striation), which is a local property in the rangefrequency plane and needs a good SNR to be correctly estimated. To improve performances, some authors ${ }^{24}$ use a linear horizontal array to apply a beamformer prior to the estimation of the spectrogram. On the contrary, for our scheme, RDC are estimated through the computation of a Fourier transform along $r$. This Fourier transform along $r$ filters sources of noise as soon as they do not present a periodic structure as a function of range. This is not the case when two passing ships are present simultaneously since the stria- tion patterns from each ship overlap in range-frequency plane. However, if the two ships have not the same direction or time of closest point of approach and speed, the striations have different shapes in the range-frequency plane (rates and periods) and image processing tools in the range-frequency plane may be applied to separate efficiently the two striation patterns.

\section{B. Sensitivity to the hypothesis of a range-independent waveguide}

The targets for our inversion scheme have to be rangeindependent. In fact, this is true for the range interval $\mathrm{R}=\left[r_{1}, r_{2}\right]$ over which the Fourier transform along $r$ is applied to compute $I_{\text {mes }}(k, f)$ from the measurements. On the one hand, if we are faced with a range dependent waveguide, we may compute the Fourier transform along $r$ on a small enough interval $\mathrm{R}=\left[r_{1}, r_{2}\right]$, for which the waveguide can be considered as invariant. On the other hand, the reduction of the range interval will decrease the processing gain produced by the Fourier transform along $r$ and the accuracy of our processing scheme will decrease. Figure 5 shows the accuracy (bias and standard deviation) versus SNR of our inversion scheme for a range interval equal to $1.8 \mathrm{~km}$, if one changes the range interval from $1.8 \mathrm{~km}$ to $\delta \mathrm{R}$, Fig. 5 will still be true but with a new shifted SNR:

$$
\mathrm{SNR}_{\delta R}=\mathrm{SNR}_{200 m}+10 \log _{10}(1800 / \delta R) .
$$

\section{Hamilton parameterization of the sediment}

In this paper, we considered a Pekeris waveguide with a semi-infinite fluid bottom layer. Hamilton Parameterization links compressional sound speed and density of the sediment [see Eqs. (15) and (16)]. It is used in our inversion scheme while sediment attenuation is neglected. This choice allows us to be faced with a single-parameter optimization of the cost function. Prior to this choice, we run simulations where the triplet consisting of the bottom properties compressional sound speed, density, attenuation are independent. The inspection of the behavior of the cost function versus these three parameters run on a large number of simulated scenarios result in the following conclusions:

(1) the sensitivity versus attenuation is weak and attenuation can not be estimated with accuracy with our inversion scheme,

(2) the estimation of density and compressional sound speed of the bottom is ill posed with a strong negative correlation between density and compressional sound speed through the cost function. This negative "acoustic based" correlation between the two properties impedes their direct estimation.

To overcome these drawbacks, we regularize the estimation by injecting an a priori information about the bottom via the Hamilton parameterization, which links compressional sound speed and density with a positive correlation. A perspective to improve both the conditioning of the inversion and its power to discriminate sub-bottom layers is to propose 
new criteria of optimization no longer based on the amount of energy contained in the wavenumber-frequency domain around the P RDC [see Eqs. (8) and (9)]. These new criteria will rely on the scalar product in the wavenumber-frequency domain between weighted versions of M RDC and P RDC, where the weighting functions applied on M RDC and $\mathrm{P}$ RDC will be chosen to maximize sensitivity versus some subsets of channel's parameters. Bayesian optimization of this scalar product seems to be a promising perspective.

\section{CONCLUSION}

This article presents a new passive inversion scheme for a single hydrophone using the noise radiated by a moving ship of opportunity. Ship noise provides frequency diversity, while the ship motion provides spatial diversity. These diversities allow to exploit the striations pattern of the spectrogram. We link striations with interference between propagative modes and we use their periodic behaviors along the range to estimate the wavenumber difference between each couple of propagative mode. These relative dispersion curves are observables to be inverted by looking for a bottom structure that produces similar theoretical dispersion curves. Match is obtained by maximizing the energy of the measurement along the theoretical dispersion curves in the wavenumber-frequency plane. Simulations draw the conclusions that (1) we are able to obtain a $+/-3 \mathrm{~ms}^{-1}$ accuracy for bottom compressional sound speed if SNR is more than $5 \mathrm{~dB}$, and (2) our scheme is only able to give a depth-average of the bottom properties without resolving the true multi-layer structure.

The algorithm is applied on experimental data recorded during the MOVEBOAT2006 experiment. The recorded data consist of the sound of a cooperative trawler performing tracks around a single hydrophone in shallow water environment along the coast of Catalonia, Spain. This emission is used as an input for our inversion algorithm, and the inversion results (track 1: $c_{b}=1790 \pm 10 \mathrm{~m} \mathrm{~s}^{-1}$ at 3 standard deviation, track 2: $c_{b}=1750 \pm 10 \mathrm{~m} \mathrm{~s}^{-1}$ at 3 standard deviation) are consistent with a core sample taken $200 \mathrm{~m}$ away from the hydrophone's location.

${ }^{1}$ A. Baggeroer, W. Kuperman, and P. Mikhalevsky, "An overview of matched field methods in ocean acoustics," IEEE J. Oceanic Eng. 18, 401-424 (1993).

${ }^{2}$ J. Hermand, "Broad-band geoacoustic inversion in shallow water from waveguide impulse response measurements on a single hydrophone: Theory andexperimental results," IEEE J. Oceanic Eng. 24, 41-66 (1999).

${ }^{3}$ J. Glattetre, T. Knudsen, and K. Søstrand, "Mode interference and mode filtering in shallow water: A comparison of acoustic measurements and modeling," J. Acoust. Soc. Am. 86, 680-690 (1989).

${ }^{4}$ G. Potty, J. Miller, J. Lynch, and K. Smith, "Tomographic inversion for sediment parameters in shallow water," J. Acoust. Soc. Am. 108, 973-986 (2000).

${ }^{5}$ B. Nicolas, J. Mars, and J. Lacoume, "Geoacoustical parameters estimation with impulsive and boat-noise sources," IEEE J. Oceanic Eng. 28, 494-501 (2003).

${ }^{6}$ J. Bonnel, B. Nicolas, J. Mars, and S. Walker, "Estimation of modal group velocities with a single receiver for geoacoustic inversion in shallow water," J. Acoust. Soc. Am. 128, 719-727 (2010).

${ }^{7}$ W. Richardson, C. Greene, Jr., C. Malme, and D. Thomson, Marine Mammals and Noise (Academic Press, San Diego, CA, 1995), 576 pp.

${ }^{8}$ B. Southall, A. Bowles, W. Ellison, J. Finneran, R. Gentry, C. Greene, Jr., D. Kastak, D. Ketten, J. Miller, P. Nachtigall, J. W. Richardson, J. A. Thomas, and P. L. Tyack, "Marine mammal noise exposure crite- ria: Initial scientific recommendations," J. Acoust. Soc. Am. 125, 2517 (2009).

${ }^{9} \mathrm{~J}$. Hildebrand, "Anthropogenic and natural sources of ambient noise in the ocean,” Mar. Ecol. Prog. Ser. 395, 5-20 (2009).

${ }^{10} \mathrm{~N}$. Carbone, G. Deane, and M. Buckingham, "Estimating the compressional and shear wave speeds of a shallow water seabed from the vertical coherence of ambient noise in the water column," J. Acoust. Soc. Am. 103, 801 (1998).

${ }^{11}$ C. Gervaise, S. Vallez, C. Ioana, Y. Stéphan, and Y. Simard, "Passive acoustic tomography: Review, new concepts and application using marine mammals," J. Mar. Biol. Assoc. U.K. 87, 5-10 (2007).

${ }^{12}$ A. Thode, "Source ranging with minimal environmental information using a virtual receiver and waveguide invariant theory," J. Acoust. Soc. Am. 108, 1582-1594 (2000).

${ }^{13}$ C. Harrison and D. Simons, "Geoacoustic inversion of ambient noise: A simple method,” J. Acoust. Soc. Am. 112, 13771389 (2002).

${ }^{14}$ M. Siderius, C. Harrison, and M. Porter, "A passive fathometer technique for imaging seabed layering using ambient noise," J. Acoust. Soc. Am. 120, 1315-1323 (2006).

${ }^{15}$ M. Siderius, H. Song, P. Gerstoft, W. Hodgkiss, P. Hursky, and C. Harrison, "Adaptive passive fathometer processing," J. Acoust. Soc. Am. 127, 2193-2200 (2010).

${ }^{16}$ A. Thode, P. Gerstoft, W. Burgess, K. Sabra, M. Guerra, M. Stokes, M. Noad, and D. Cato, "A portable matched-field processing system using passive acoustic time synchronization," IEEE J. Oceanic Eng. 31, 696-710 (2007).

${ }^{17}$ D. Battle, P. Gerstoft, W. Kuperman, W. Hodgkiss, and M. Siderius, "Geoacoustic inversion of tow-ship noise via near-field-matched-field processing," IEEE J. Oceanic Eng. 28, 454-467 (2005).

${ }^{18}$ M. Nicholas, J. Perkins, G. Orris, L. Fialkowski, and G. Heard, "Environmental inversion and matched-field tracking with a surface ship and an L-shaped receiver array," J. Acoust. Soc. Am. 116, 2891-2901 (2004).

${ }^{19}$ R. Koch and D. Knobles, "Geoacoustic inversion with ships as sources," J. Acoust. Soc. Am. 117, 626-637 (2005).

${ }^{20}$ S. Jesus, C. Soares, E. Coelho, and P. Picco, "An experimental demonstration of blind ocean acoustic tomography," J. Acoust. Soc. Am. 119, 1420-1431 (2006).

${ }^{21}$ D. Tollefsen and S. Dosso, "Bayesian geoacoustic inversion of ship noise on a horizontal array," J. Acoust. Soc. Am. 124, 788-795 (2008).

${ }^{22}$ S. Stotts and R. Koch, "Geoacoustic inversions and localizations with adaptively beam-formed data from a surface ship of opportunity source," J. Acoust. Soc. Am. 127, 84-95 (2010).

${ }^{23}$ S. Stotts, R. Koch, S. Joshi, V. Nguyen, V. Ferreri, and D. Knobles, "Geoacoustic Inversions of Horizontal and Vertical Line Array Acoustic Data From a Surface Ship Source of Opportunity," IEEE J. Oceanic Eng. 35, 79-102 (2010).

${ }^{24} \mathrm{~K}$. Heaney, "Rapid geoacoustic characterization using a surface ship of opportunity," IEEE J. Oceanic Eng. 29, 88-99 (2004).

${ }^{25}$ A. Turgut, M. Orr, and D. Rouseff, "Broadband source localization using horizontal-beam acoustic intensity striations," J. Acoust. Soc. Am. 127, 73-83 (2010).

${ }^{26} \mathrm{D}$. Rouseff and L. Zurk, "Striation-based beamforming using the waveguide invariant for passive sonar," J. Acoust. Soc. Am. 129, 2601 (2011).

${ }^{27} \mathrm{Q}$. Ren and J. Hermand, "Striation processing for sediment geoacoustic characterization," J. Acoust. Soc. Am. 129, 2426 (2011).

${ }^{28} \mathrm{G}$. D'Spain and W. Kuperman, “Application of waveguide invariants to analysis of spectrograms from shallow water environments that vary in range and azimuth," J. Acoust. Soc. Am. 106, 2454-2468 (1999).

${ }^{29}$ E. Hamilton, "Geoacoustic modeling of the sea floor," J. Acoust. Soc. Am. 68, 1313-1340 (1980).

${ }^{30}$ See website of European Project Euromarsin, http://www.eu-seased.net (Last viewed April 21, 2011). This site presents an archive of sediment core samples collected along the European sea coast.

${ }^{31}$ S. Vallez, C. Gervaise, A. Khenchaf, Y. Stéphan, and M. André, "Inversion géoacoustique d'un canal trés petits fonds à partir des navires en mouvement traitement incohérent (Very shallow water geoacoustic inversion with ship noise using incoherent signal processing tools)," Trait. Signal 25, 151-163 (2008).

${ }^{32} \mathrm{C}$. Erbe, "Underwater noise of whale-watching boats and potential effects on killer whales (orcinus orca), based on an acoustic impact model," Mar. Mamm. Sci. 18, 394-418 (2002). 
${ }^{33} \mathrm{C}$. Harrison, "The relation between the waveguide invariant, multipath impulse response, and ray cycles," J. Acoust. Soc. Am. 129, 2863-2877 (2011).

${ }^{34}$ F. Jensen, W. Kuperman, and B. Michael, Computational Ocean Acoustics (AIP, New York, 1994), 595 pp.

${ }^{35} \mathrm{H}$. Song and A. Baggeroer, "The resolution of modal doppler shifts in a dispersive oceanic waveguide," J. Acoust. Soc. Am. 88, 268-282 (1990).

${ }^{36} \mathrm{P}$. Lim and J. Ozard, "On the underwater acoustic field of a moving point source. I. Range-independent environment," J. Acoust. Soc. Am. 95, 131-137 (1994).

${ }^{37}$ E. Westwood, C. Tindle, and N. Chapman, "A normal mode model for acousto-elastic ocean environments," J. Acoust. Soc. Am. 100, 3631 (1996).
${ }^{38}$ F. Hlawatsch and G. Boudreaux-Bartels, "Linear and quadratic time-frequency signal representations," IEEE Signal Process. Mag. 9, 21-67 (1992).

${ }^{39}$ See http://www.marinetraffic.com/ais/ (Last viewed October 28, 2011), dedicated to access shipping traffic in real time world wide coverage thanks to Automatic Identification System.

${ }^{40}$ S. Stergiopoulos, Advanced Signal Processing Handbook: Theory and Implementation for Radar, Sonar, and Medical Imaging Real Time Systems (Chemical Rubber Company Press, Boca Raton, FL, 2000), 752 pp.

${ }^{41}$ R. Moose, D. McCabe, and H. VanLandingham, "Passive tracking of underwater maneuvering targets," IEEE Conf. Decision Control 17, 99-103 (1978).

${ }^{42}$ J. Nitsche and R. Spooner, "Performance estimates of doppler tracking systems” IEEE Int. Conf. Eng. Ocean Environ. 38, 86-91 (1973). 